\begin{tabular}{|c|c|c|}
\hline \multirow{2}{*}{ DVल } & $\begin{array}{l}\text { International Journal of Current Research in } \\
\text { Biosciences and Plant Biology }\end{array}$ & $=0$ \\
\hline & Volume $4 \bullet$ Number 1 (January-2017) • ISSN: 2349-8080 (Online) & \\
\hline $\begin{array}{l}\text { EXCELLENT } \\
\text { PUBLISHERS }\end{array}$ & Journal homepage: www.ijcrbp.com & wawe.jictop com \\
\hline
\end{tabular}

\title{
Screening of Organisms and Optimization of Culture Media for the Production of Spirogyra
}

\author{
Hammad Ashraf ${ }^{1 *}$, Mehwish Jaffer ${ }^{2}$ and Shabnum Shaheen ${ }^{2}$ \\ ${ }^{I}$ Department of Botany, Government College of Science, Wahdat Road, Lahore, Pakistan \\ ${ }^{2}$ Department of Botany, Lahore College for Women University, Lahore, Pakistan \\ *Corresponding author.
}

\begin{tabular}{|c|c|}
\hline Abstract & Article Info \\
\hline \multirow{5}{*}{$\begin{array}{l}\text { The present study is concerned with the selection of organism and optimization of culture } \\
\text { media for algal biomass production. Samples of different species of algae were collected } \\
\text { and identified from different areas of Lahore. The rate of growth of these algal species } \\
\text { was compared in A-Z medium. It was found that the rate of biomass production of all the } \\
\text { species was increased with increase in time. However, Spirogyra exhibited maximum } \\
\text { production of algal biomass in } 15 \text { days of incubation. Different culture media, including } \\
\text { A-Z media, Bristol's media and Bristol's soil media were employed for mass production. } \\
\text { Among them, Bristol's soil media was found the best media, as it supplied maximum } \\
\text { production of algal biomass }(10.5 \mathrm{~g} / \mathrm{L}) \text {. Moreover, the production of biomass was reached } \\
\text { optimum after } 14 \text { days of incubation in Bristol's soil media. }\end{array}$} & $\begin{array}{l}\text { Accepted: } 23 \text { December } 2016 \\
\text { Available Online: O6 January } 2017\end{array}$ \\
\hline & Keywords \\
\hline & Algal biomass production \\
\hline & $\mathrm{A}-\mathrm{Z}$ media \\
\hline & $\begin{array}{l}\text { Bristol's media } \\
\text { Spirogyra }\end{array}$ \\
\hline
\end{tabular}

\section{Introduction}

Algae are unique group of living photosynthetic organisms that are present in every type of environment, such as freshwater, river, lakes on rocks in ice and air. Water covers two-third surface of our earth, and thus the algae covers the greatest area (Khola and Ghazala, 2012). Now-a-days algae is immensely important in environmental purification because it is inexpensive biomaterial that is used for the removal of oxides of sulphur and nitrogen, heavy metal, waste water, and $50 \%$ fixation of carbon dioxide (Negoro et al., 1991; Yoshihara et al., 1996; Ogbonna et al., 2000).

Algal biomass is considered as the sustainable source of energy. Its large scale production could sustain the global demands, environmentally and economically. Algae can increase their biomass tremendously using few nutrients and less energy requirements even some species can double their biomass only within 5 hours (Huber, 2009). Algal culturing is the basic and essential requirement for the study of molecular structure, cell biology, cell biochemistry, ecology, genetics, etc. as it cannot be possible without culturing. Munir et al. (2015) studied high productivity of algal mass depend on various abiotic factors including nutrient availability. Over the last decades, culturing techniques have advanced considerably (Kim et al., 2002). Number of culturing techniques has been evolved by which high yield algal cultures can be achieved. Basically, a high yield culture solely depends upon a good nutrition source. A potential source of nutrition in culture media 
would enable to flourish the algal culture. Considering the above-mentioned scenario, the present study was designed to screen the algal species that were most suitable for algal biomass production, and second different media were evaluated for the better production of algal biomass.

\section{Materials and methods}

The present research work was conducted during 20152016 in Botany Research Lab Govt. College of Science, Wahdat Road, Lahore. The study was confined for the selection of algal species and optimization of different cultural conditions for the production of algal biomass. Following protocol was followed for this research study.

\section{Collection and taxonomic study of algal specimen}

Different algal specimens were collected in a plastic bag from different areas of Lahore Table 1. The species were then taxonomically identified according to Prescott 2007. The identified species were then cultured and effect of different parameters on algal growth was studied.

Table 1. Algae sample collects from different localities.

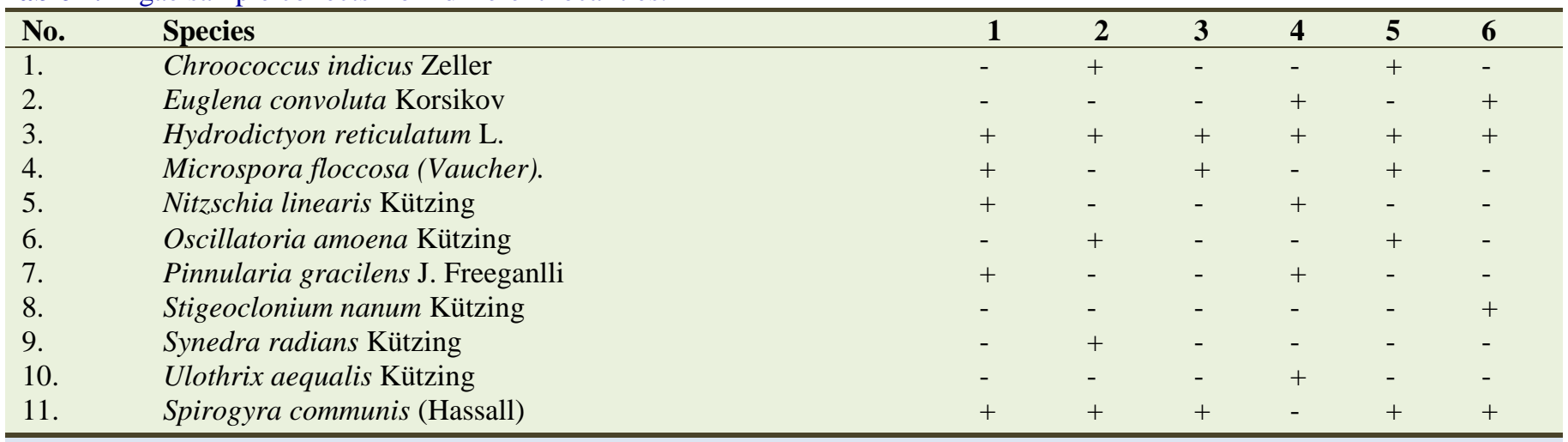

1. Head bloke next to Gor Gulāb Singh; 2, 5, 6. River Ravi; 3. PU fountains; 4. Bagh-e-Jinnah fountain.

\section{Production of algal biomass}

For the production of algal biomass in research facility the examination was completed in $1000 \mathrm{ml}$ container containing culture media. Two gram of algal biomass was then added to beaker. The beakers were then offered to daylight for $6 \mathrm{hrs}$ term each day. The beakers were then placed in Laboratory for ideal development of algal species. The samples were then separated to expel water substance and weighed after $24 \mathrm{hrs}$. Triplicates were maintained for each analysis. The slow change in growth was examined for 15 days.

\section{Culture media for algal biomass}

Different culture media were used for the algal biomass production. The media used were as follows:

\section{A-Z media (Prescott, 2007)}

2. Bristol's media (Alam et al., 2015 )

3. Bristol's soil media (Bristol media along with $10 \mathrm{~g}$ soil)

\section{Statistical analysis}

Treatment effects were compared by the method of Snedecor and Cochrane (1980).

\section{Results and discussion}

The culturing of algae was done in order to select the most economy methods and easily available sources. Different algal sample were collected from different localities of Lahore to regulate the species diversity. It was observed that algae vary by changing locality, but the most dominating species that were found in almost all samples were Hydrodictyon, Spirogyra and Microspora (Fig. 1). Due to the dominant abundance and convenient availability of these species, these three were selected for further experimental analysis. The culturing was done keeping in mind the commercial and economical perspective.

\section{Collection and identification of organism}

The algal specimens were collected from different areas of Lahore and algal species were examined under 
compound microscope. The algal specimens were identified following morphological characters as given by Prescott (2007) and Zarina et al. (2009). Three filamentous species: Spirogyra, Hydrodictyon and Microspora were identified and selected for further studies.

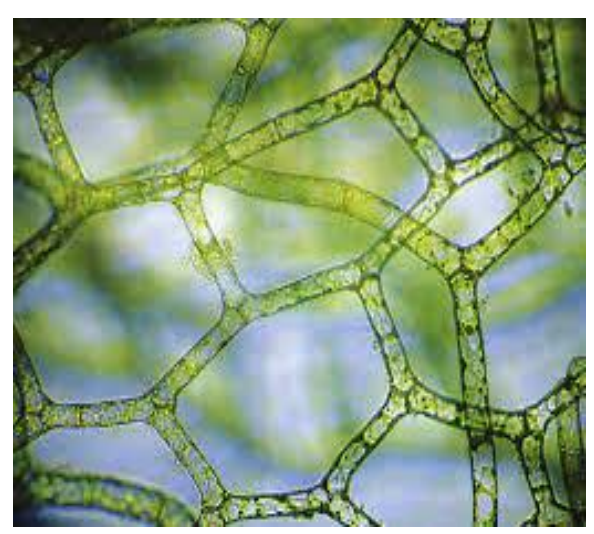

Hydrodictyon

Fig. 1: Selected algal species for biomass production.

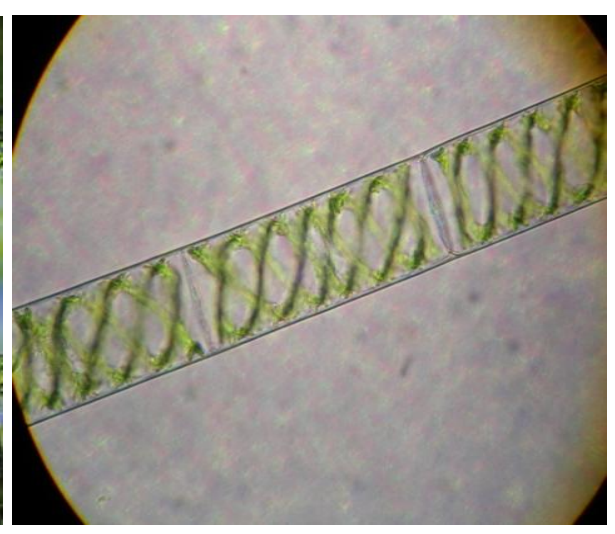

Spirogyra

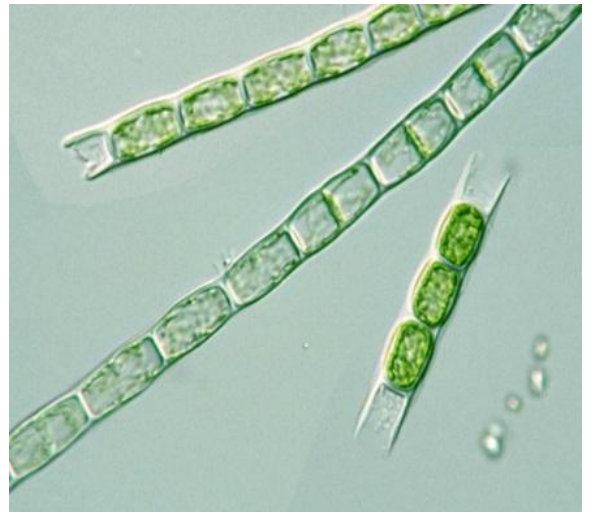

Microspora

\section{Screening of algal species}

Fig. 2 shows the comparative study of algal biomass production. The three species of algae: Hydrodictyon, Microspora and Spirogyra were cultured in Bristole's soil media and growth rates were studied for 20 days. The growth of all algal species was increased with increase in the incubation period. The growth of Hydrodictyon reached in decline phase after 20 days, while the growth of Microspora reached in decline phase in 8 days after having insignificant growth results. However, the growth of Spirogyra was found to be significant $(9.8 \mathrm{~g} / \mathrm{L})$ as compared to Hydrodictyon $(5.2 \mathrm{~g} / \mathrm{L})$ and Microspora $(2.0$ $\mathrm{g} / \mathrm{L}$ ), respectively. It might be due to the fact that the Spirogyra filaments grow well in the components that were provided in the form of media (Negoro et al., 1991). However, the other algal species gave insignificant production of biomass that might be due to the less rapid growth of these species in the cultural conditions provided as compared to the Spirogyra.

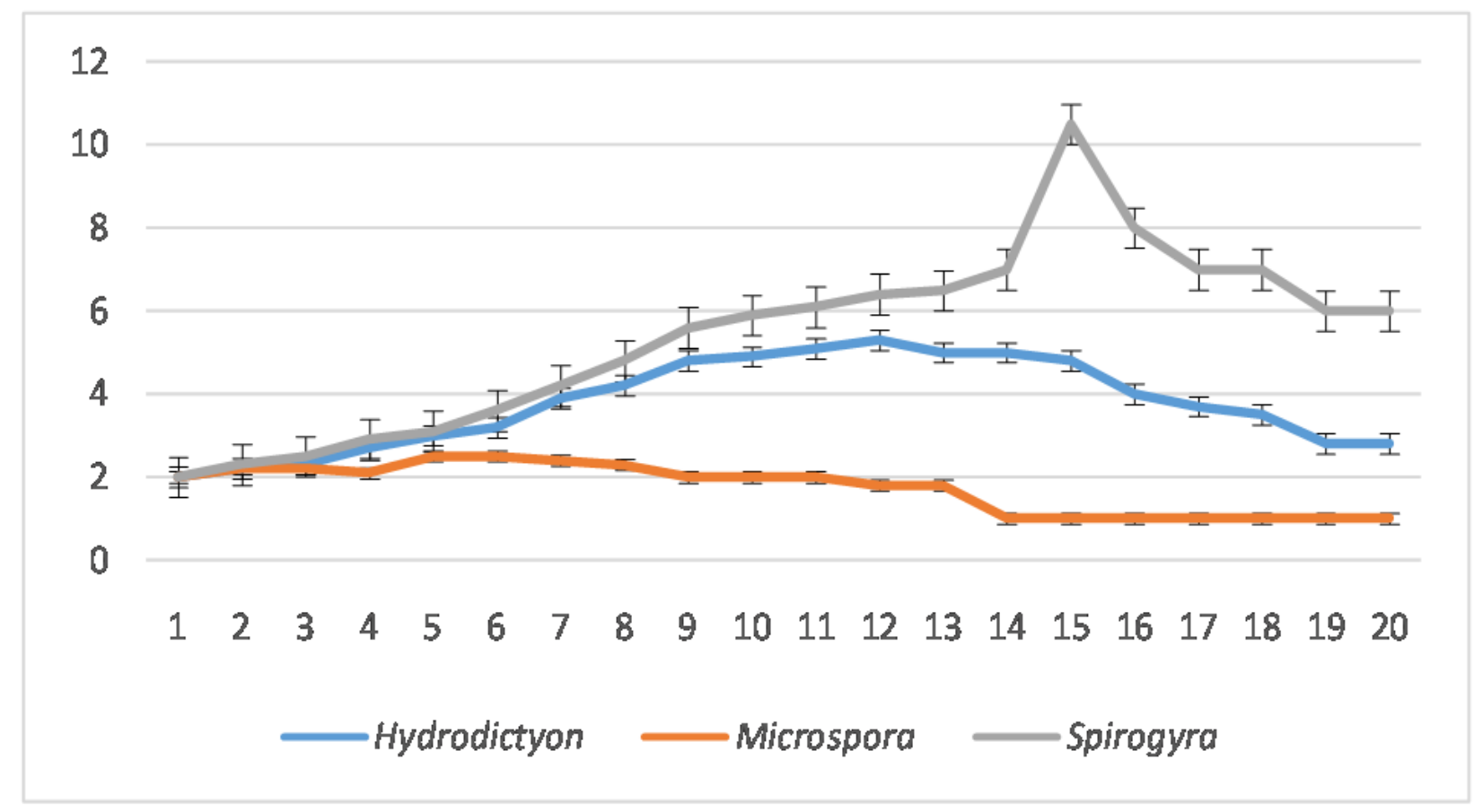

Fig. 2: Comparative study of algal biomass growth. 
Fig. 3 indicates the effect of different cultured media on algal biomass growth. Three cultured media M1 (A-Z media), M2 (Bristol's), M3 (Bristol's soil media) were used for algal biomass production. Among all the tested media, Bristol's soil media gave $10.5 \mathrm{~g} / \mathrm{L}$ as maximum growth whereas A-Z media and Bristol's media gave the biomass $8.4 \mathrm{~g} / \mathrm{L}$ and $7.0 \mathrm{~g} / \mathrm{L}$, respectively. These results showed that the Bristol's soil media was best media for maximum yield of Hydrodictyon. The composition of this media was correlated with the requirements of our selected species and enhanced its growth. Similar results were recorded by Alam et al. (2015). They selected four algal species and studied their growth in BM soil media. All the species grown best in BM soil media, because this medium contains all the necessary nutrients for ideal algal biomass production. Findings of current research were also concordant with results of Yeh and Chang (2012) as they cultured algae under different media for biomass production. They found Bristol's soil media was best for algal culturing.

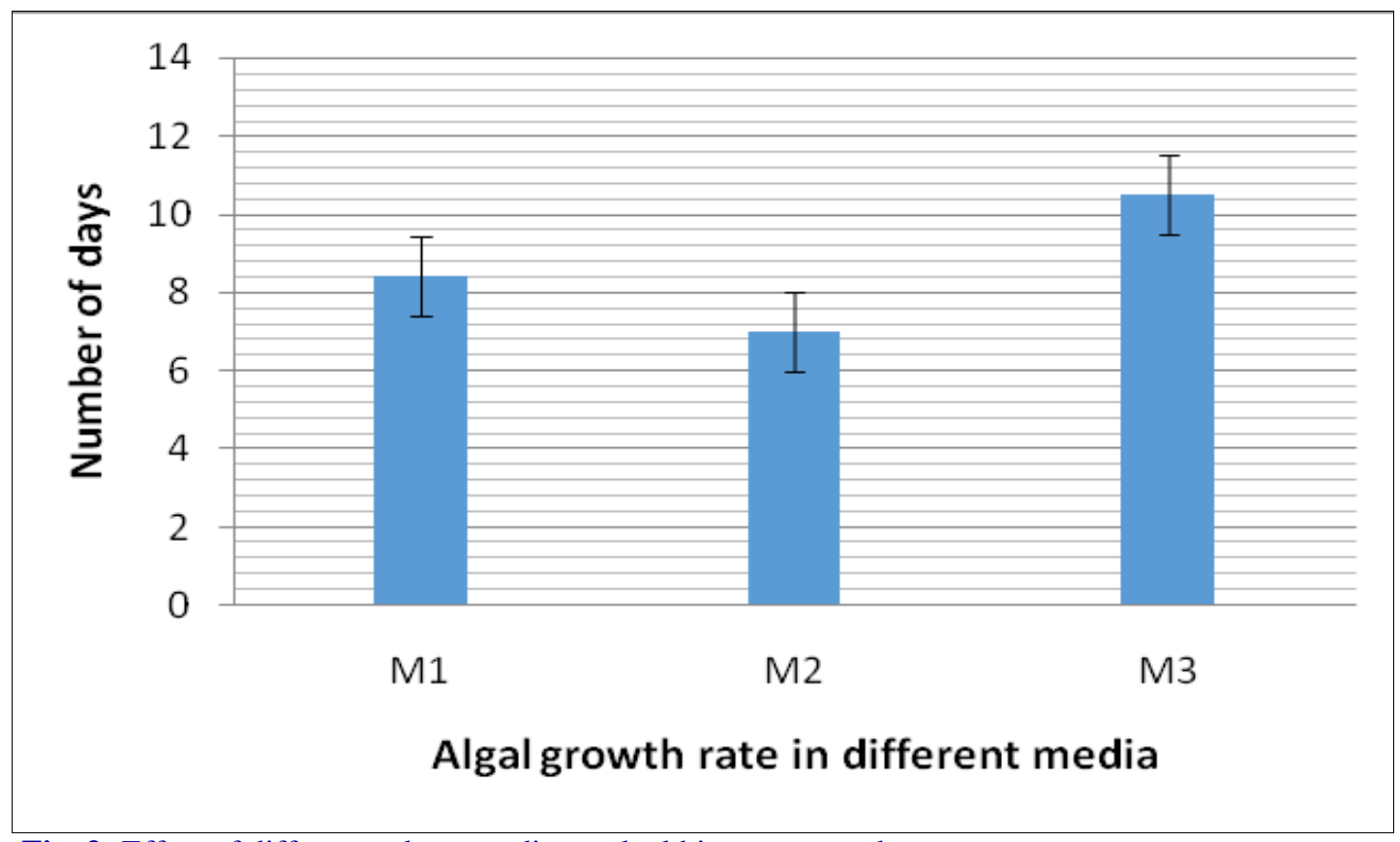

Fig. 3: Effect of different culture media on algal biomass growth.

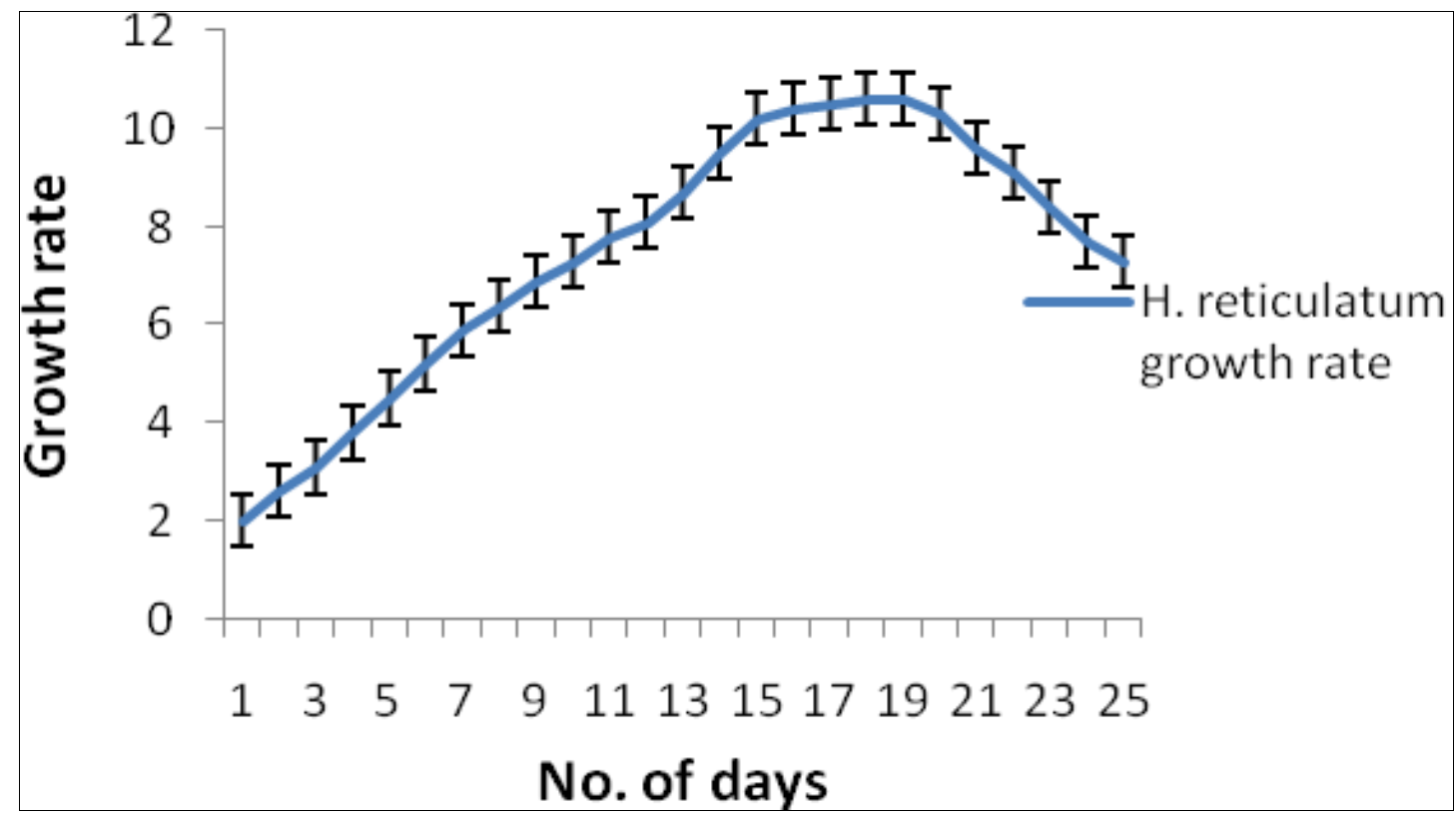

Fig. 4: Growth rate of Hydrodictyon biomass production. 


\section{Rate of Spirogyra biomass production}

For studying the growth rate and biomass production, Spirogyra was cultured for 25 days in the Bristol soil medium. Results showed that algal growth increases with increase in the incubation period and reached optimum at 15 days after incubation. Further increase in the incubation period has no significant effect on the mass production rather it declined after 18 days of incubation period. It might be due to the fact that the depletion of the nutrients as well as increase in the toxic metabolites in the growth medium. These toxic compounds may retard the growth of the organism as well as it also cause death of the organism (Prescott, 2007; Rai et al., 2013). Therefore, 15 days of incubation was selected for optimum growth of Spirogyra.

\section{Conclusion}

From the present study it was concluded that among the filamentous algae Spirogyra can be used for mass production of algae. The Bristol's soil media can be used for optimum growth of Spirogyra. The algal biomass production reached optimum 15 days after incubation period. The algal production can be significantly increased by optimization of cultural conditions. This leads to fulfill the demand of starvation as well as other economic importance of our country.

\section{Conflict of interest statement}

Authors declare that they have no conflict of interest.

\section{References}

Alam, A., Saleem, U., Alam, S., Shah, H. U., Aftab, S., Siddiq, M., Manzoor, N., 2015. Influence of culture media and carbon sources on biomass productivity and oil content of the algae Sirogonium sticticum, Temno gyrareflexa, Uronemaelo nggaatum, and Chroococcus turgidus. Turk. J. Bot. 39, 1405-1416.

Huber, G.W., Dale, B.E., 2009. Biofuels: Grassoline at the pump. Sci. Amer. 301(1), 52-59.

Khola, G., Ghazala, B., 2012. Biodiesel production from algae. Pak. J. Bot. 44(1), 379-381.

Kim, J. N., Suh, I. S., Hur, B. K., Lee, C. G., 2002. Simple monodimensional model for linear growth rate of photosynthetic microorganisms in flat-plate photobioreactors. J. Microbiol. Biotechnol. 12(6), 962-971.

Munir, N., Imtiaz, A., Sharif, N., Naz, S., 2015. Optimization of growth conditions of different algal strains and determination of their lipid content. J. Anim. Plant Sci. 25(2), 546-553.

Negoro, M., Shioji, M., Miura, Y., 1991. Growth of microalgae in high $\mathrm{CO}_{2}$ gas and effects of SOx and NOx. J. Appl. Biochem. Biotechnol. 28(29), 877886.

Ogbonna, J. C., Yoshizawa, H., Tanaka, H., 2000. Treatment of high strength organic wastewater by a mixed culture of photosynthetic microorganisms. J. Appl. Phycol. 12, 277-284.

Prescott, G. W., 2007. Algae of the Western Great Lakes Area. $9^{\text {th }}$ Edn. John Wiley and Sons, New York.

Rai, U., Deshari, G., Rai, B., Bhattarain, K. Dhakal, R. P., Rai, S. K., 2013. Isolation and culture condition optimization of Chlorella vulgaris. Nep. J. Sci. Technol. 4(2), 43-48.

Snedecor, G.W., Cochrane, W.G., 1980. Statistical Methods. $7^{\text {th }}$ Edn. Iwoa state University Press, Ames, Iowa.

Yeh, K. L., Chang, J. S., 2012. Effects of cultivation conditions and media composition on cell growth and lipid productivity of indigenous microalga Chlorella vulgaris ESP-31. Bioresour. Technol. 105, 120-127.

Yoshihara, K., Nagase, H., Eguchi, K., Miyamoto, K., 1996. Biological elimination of nitric oxide and carbon dioxide from flue gas by marine microalgae NO4 - 113 cultivated I long tubular photobioreactor. J. Ferment. Bioeng. 82, 351-354.

Zarina, A., Hasan, M. U., Shameel, M., 2009. Diversity of freshwater green macro algae in the Punjab and neighboring areas of Pakistan. Pak. J. Bot. 41(1), 277-291.

\section{How to cite this article:}

Ashraf, H., Jaffer, M., Shaheen, S., 2017. Screening of organisms and optimization of culture media for the production of Spirogyra. Int. J. Curr. Res. Biosci. Plant Biol. 4(1), 32-36.

doi: http://dx.doi.org/10.20546/ijcrbp.2017.401.005 